\title{
O Proxecto Abalar e o Libro Dixital en Galicia (Edixgal)
}

\section{The Project Abalar and the Digital Book in Galicia (Edixgal)}

\author{
Eduardo Rodríguez-Machado*, Emilio J. Veiga** Mercedes González-Sanmamed*** \\ *Universidad Internacional de la Rioja, **Universidad de Santiago de Compostela, ***Universidade da Coruña
}

\begin{abstract}
Resumo
O noso centro participa no Proxecto Abalar e dende os seus inicios vimos utilizando diferentes ferramentas para a mellora da calidade educativa. Neste curso abrangue 4 aulas de $5^{\circ}$ e $6^{\circ}$ de Educación Primaria cun número total de alumn@s de 92. Tamén participamos no proxecto Edixgal trata de proporcionar aos centros educativos a posibilidade de presentar un proxecto integral para a incorporación de materiais dixitais en todas as materias de $5^{\circ}$ e $6^{\circ}$ de educación primaria e $1^{\circ}$ de ESO, para isto dispoñerán do apoio da Administración en forma de provisión de materiais e libros dixitais, así como dunha contorna virtual de aprendizaxe que permita desenvolver todo o potencial e dea soporte ao proxecto.
\end{abstract}

Palabras claves: Proxecto Abalar, Edixgal, integración, Tics, Competencias Dixitais.

\begin{abstract}
Our center takes part in the Project Abalar and from his beginnings we come using different tools for the improvement of the educational quality. In this course it covers 4 classrooms of 5th and 6th of Primary Education with a total number of alumn@s of 92. We also inform in the project Edixgal about trade of providing the educational centers with the possibility to present an integral project for the incorporation of digital materials in all the matters of 5 th and 6th of primary education and 1 st of THAT, for this they will have the support of the Administration in the form of provision of materials and digital books, as well as a virtual congate of learning that allows to develop all the potential and gives support to the project.
\end{abstract}

Keywords: Project Abalar, Edixgal, integration, Tics, Digital competences

\section{Introducción}

O mundo das TIC é hoxe en dia unha enorme fonte de recursos, imposíbel de abarcar en toda a súa dimensión por muitas razóns, entre outras: a inxente cantidade de posibilidades que ofrece; o efímero de algunhas das propostas que a priori poden captar o noso interese; o esforzo que require o manexo de algunhas das aplicacións e servizos se desexamos tirar-lle toda a sua potencialidade; a existéncia de aplicativos pouco flexíbeis á hora de traballar en integración con diversos medios; a dificuldade en discriminar entre o bombardeo de materiais de ínfima calidade aqueles recursos realmente valiosos e ben deseñados; a dificuldade de permanecer constantemente ao tanto dos avances que van aparecendo a un ritmo imposíbel de manter. Por todo isto é conveniente que pensemos realmente que é o que demandamos das TIC, que posibilidades ofrecen, para facer que, en que aspectos mellora o noso sistema educativo e en que casos pode resultar un atranco. Desde este ponto de vista, esta publicación quere ser un espazo no que se favoreza o coñecimento dos recursos que temos neste momento, incorporando de forma dinámica os cámbios que se vaian producindo.

O proxecto Edixgal diríxese aos centros que están na Rede Abalar, centros cunha cultura dixital afianzada como parte do seu proxecto de centro, apoiado e coñecido pola comunidade educativa e, en especias polas familias, que se verán beneficiadas ademais co aforro en custos derivados dos materiais educativos. Por outra banda, posibilitarase o maior aproveitamento do equipamento das aulas dixitais do proxecto.

\section{O Proxecto Abalar}

O Proxecto Abalar maniféstase no uso personalizado dun ordenador portátil por parte do alumnado de $5^{\circ}$ e $6^{\circ}$ de primaria e $1^{\circ}$ e $2^{\circ}$ da ESO acompañada da posta en marcha do que se deu en chamar as aulas dixitais do século XXI, é dicir, aulas dotadas dunha axeitada infraestrutura tecnolóxica e de conectividade por banda ancha.

O Proxecto Abalar ten a súa orixe na palabra celta "Abal", que significa mazá, a froita da sabedoría, e no termo galego "Abalar" para transmitir a mensaxe de promover e facilitar o movemento, o cambio e a transformación na educación.

Abalar é o proxecto que substancia a estratexia para a integración plena das TIC na práctica educativa en Galicia, como unha das áreas prioritarias de intervención da Consellería de Educación e Ordenación Universitaria.

Este ambicioso programa, que se articula en cinco eixes de intervención:

. dotación de aulas dixitais,

. desenvolvemento da conectividade a Internet dende o centro educativo e dende os fogares e interconectividade dentro da aula,

. formación do profesorado,

. xeración e acceso a contidos educativos dixitais de carácter curricular, e implicación dos alumnos e as súas familias no uso e aproveitamento destes recursos.

As nosas aulas Abalar contan cun miniportátil para cada alumno cun armario de carga, unha PDI e canón de última xeración e un ordenador do profesor, todos estes elementos están comunicados por wifi-Abalar e o servidor do centro. 


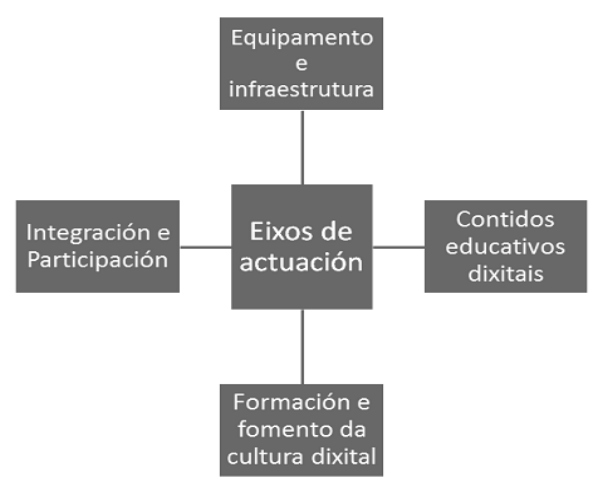

Figura 1. Eixes do Proxecto Abalar

O proxecto busca maximizar o aproveitamento dos recursos, coordinar e impulsar un cambio no modelo educativo apoiado na formación do profesorado e a modernización do ensino que suporá a conversión dos colexios e institutos galegos en centros educativos dixitais.

A estratexia do proxecto Abalar xira arredor do concepto de centro educativo dixital. $\mathrm{O}$ centro educativo dixital supera o concepto de centro educativo tradicional e persegue dispor de recursos humanos e pedagóxicos, así como de infraestruturas e servizos axeitados para o uso cotián da tecnoloxía por parte de todos os axentes da comunidade educativa, na actividade docente, de aprendizaxe e administrativa.

Todo o proceso está orientado a apoiar a xestión do cambio de modelo de centro educativo tradicional ao novo centro educativo dixital, e para iso, a continuación, móstranse os eixes de actuación do proxecto:

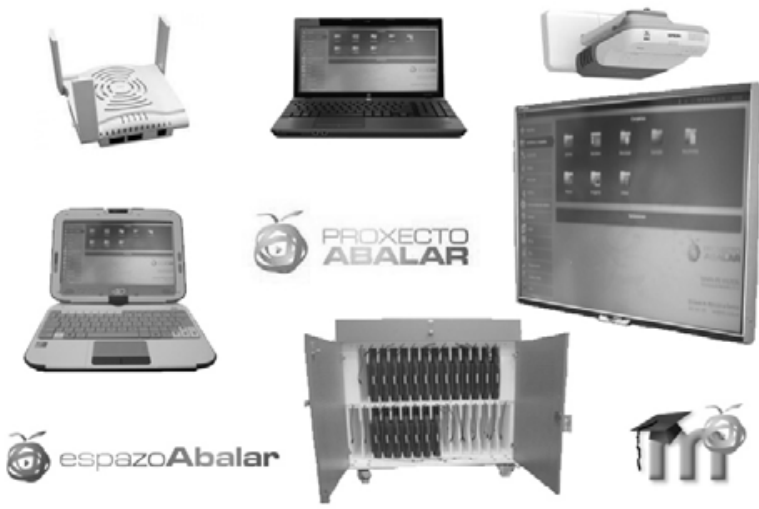

Figura 2. Elementos dunha Aula Abalar

\section{Situación actual do Proxecto Abalar}

Desde 2010 o Proxecto Abalar avanzou en:

No eixo de Equipamento e infraestruturas, 2300 aulas equipadas e 52.000 alumnos beneficiados (59\% dos 87000 alumnos de $5^{\circ}$ e $6^{\circ}$ de Educación Primaria de $1^{\circ}$ e $\left.2^{\circ} \mathrm{ESO}\right)$.

No eixo de Formación e fomento da cultura dixital formáronse a máis e 23000 docentes, e impartironse actividades destinadas a alumnado, profesorado e familias (Navega con Rumbo), e preto de 900 centros.
No eixo de Contidos Educativos Dixitais, o Repositorio de Contidos Dixitais de espazoAbalar ten a disposición da comunidade educativa case que 2500 recursos educativos dixitais complementarios (para todos os iniveis educativos e en 7 idiomas)

No eixo de Participación e Difusión, púxose en marcha o espazoAbalar, o punto de encontro na rede da comunidade educativa con máis de 1,5 millón de visitas anuais, e estase a estender aos centros educativos o uso de novas canles de comunicación a través da plataforma abalarMovil, que na actualidade está disponible en 107 centros.

Investimento: Este ano o Proxecto Abalar sumará un investimento total de 45 millones de euros.

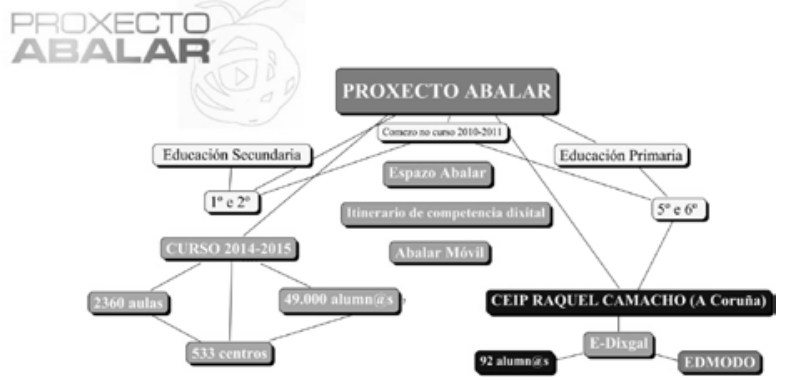

Figura 3. Situación actual de Proxecto Abalar

\section{Formación e fomento da cultura dixital}

Ao longo do curso 2014/2015, dentro do Plan de Formación do Profesorado, estivose a impartir formación destinada ao profesorado participante no proxecto, en particular:

- Formación sobre o proxecto de Libros Dixitais E-Dixgal (19 actividades que benefician a preto de 340 docentes).

- Formación en centros para profesorado Abalar (máis de 50 actividades de formación, que supoñen preto de 2.000 horas de formación).

- Cursos presenciais de tecnoloxías de información e da comunicación, emprego didáctico das EDI e ferramentas colaborativas para profesorado Abalar (12 cursos que benefician a máis de 200 docentes).

- Cursos a distancia de tecnoloxías de información e da comunicación para profesorado Abalar nas que participan cerca de 300 docentes.

- Adicionalmente, se desenvolveu unha nova edición da iniciativa "Navega con Rumbo" para a formación e concienciación do profesorado e do alumnado nos bos hábitos do uso da rede, destinada neste curso a máis de 150 centros, e que se impartiu xa en máis de 900 centros para máis de 50.000 cidadáns.

\section{Libro dixital (E-DIXGAL)}

Co obxectivo de por en marcha o libro dixital nos centros educativos galegos, o proxecto E-DIXGAL arrancou este curso 2014/2015, incorporando a máis de 2.300 alumnos de $5^{\circ}$ de primaria de 84 centros Abalar que se adscribiron á iniciativa. 
Docentes e alumnos dos centros implicados desenvolveron a súa actividade educativa diaria nun entorno virtual de aprendizaxe que lles permite acceder a contidos dixitais para $5^{\circ}$ de primaria de dous provedores, a editorial EDEBÉ e a empresa de contidos dixitais Netex.

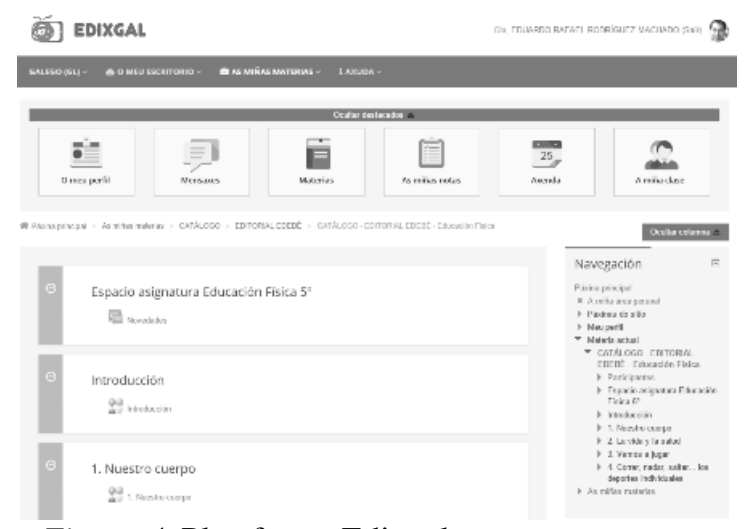

Figura 4. Plataforma Edixgal

Os docentes poden elaborar a súa propia “mochila dixital” seleccionando a través da plataforma dixital os contidos formativos e podendo incorporar os materiais complementarios que desexen, así como contidos de elaboración propia. Cómpre recordar que estes centros, integrados no proxecto Abalar, teñen tamén a súa disposición o espazoAbalar con máis de 2.500 recursos educativos dixitais complementarios en sete idiomas.

Os alumnos poden acceder ao material seleccionado polo profesor tanto a través dunha conexión a internet (modo online) como dende o seu netbook (modo offline). Deste xeito, garántese que os alumnos e as alumnas que non dispoñan de conexión a Internet desde as súas casas poidan seguir o curso sen dificultade. De feito, todo o avance que realicen sen conexión será actualizado de maneira automática na plataforma en canto o netbook volva ter conexión de rede.

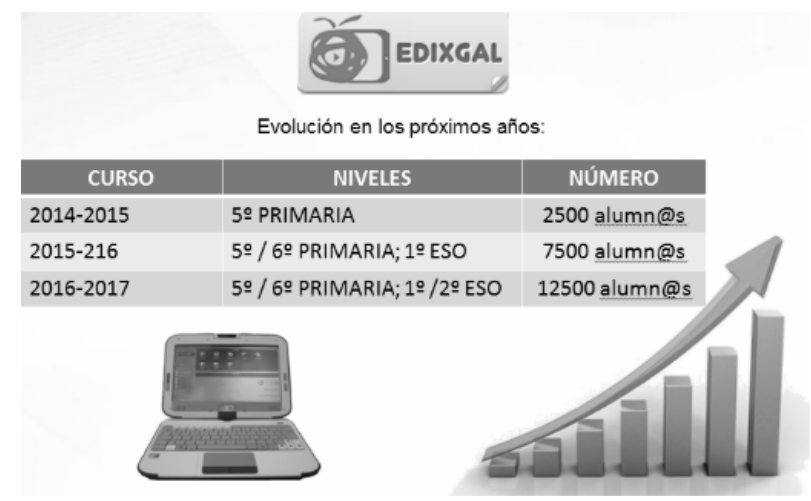

Figura 5. Evolución Edixgal

O acceso á plataforma virtual de aprendizaxe é posible a través de calquera equipo con conexión a internet sempre que se faga uso das claves de acceso que lle serán entregadas ao alumnado no centro. Porén o alumno que así o desexe, ten a posibilidade de utilizar tamén na súa casa o netbook (ordenador portátil) que emprega na clase, para o que deberá solicitar no seu centro un formulario de préstamo do mesmo, que devolverá asinado no prazo máis breve posible.

A utilización do ordenador portátil e das ferramentas e contidos dixitais instalados no mesmo é gratuíta para o alumno. As familias comprométense a que o alumnado realice un uso dilixente do equipamento, ao coidado dun equipo público, que poderá ser usado noutros cursos por outros alumnos, e a unha utilización vinculada á actividade educativa para a que é cedido.

\section{Características da nova convocatoria Edixgal}

Dirixida a centros da rede Abalar nos cursos de $5^{\circ} \mathrm{EP}$ e $1^{\circ} \mathrm{ESO}$ (Curso 2015-2016).

Incorporaranse 50 novos centros. Posibilidade de extensión.

Compromiso dos centros:

- Proxecto concretando a implantación no centro.

- Participación activa da comunidade educativa.

- Persoa coordinadora.

- Conectividade: 2 Mbp

Compromiso da administración:

- Asesoramiento, asistencia técnica, seguimento e apoio.

- Recoñecemento como innovación educativa.

- Entorno virtual de aprendizaxe.

- Contidos dixitais gratuítos. Gratuidade para ás familias.

\section{Nova Dixitalización das aulas}

Kits de aula dixital (Curso 2015-2016)

Obxetivos.

- Abalar amplia o seu alcance cunha nova dotación Kits de aula dixital: composta por encerado dixital interactivo, vídeo proxector e ordenador portátil para o posto de profesor, ademáis da conectividade da aula. Cómpre destacar que esta dotación de equipamento nos centros educativos participantes, é moi valorada e recoñecida polo profesorado.

- O obxectivo desta actuación proxecto é despregar este equipamente en todas as aulas de centros públicos de Galicia nas que se imparte $5^{\circ}$ e $6^{\circ}$ Educación Primaria, e $1^{\circ}, 2^{\circ}, 3^{\circ}$ e $4^{\circ}$ de Educación Secundaria Obrigatoria, e que na actualidade non conten co devandito equipamento.

- A previsión é instalar este equipamento en 2800 aulas dun 870 centros públicos.

Unha vez completada esta iniciativa beneficiaranse dela 50.000 alumnos, que sumados aos que xa están integrados no proxecto, suporá ampliar o alcance de Abalar a máis de 100.000 alumnos.

\section{A nosa experiencia TICs no CEIP Raquel Camacho (A Coruña)}

O Proxecto Abalar se desenvolve no noso centro dende o curso 2011-2012 de forma continuada rematando a súa implantación no 2012-2013. Abarca 4 aulas de $5^{\circ}$ e $6^{\circ}$ de Ed. Primaria con un número total de 92 alumn@s.

No curso 2014-2015 o proxecto abalar transcorreu con normalidade. Ás aulas $6^{\circ} \mathrm{A}$ e $6^{\circ} \mathrm{B}$ tiveron moi poucas incidencias, en cambio as aulas de $5^{\circ} \mathrm{A}$ e $5^{\circ} \mathrm{B}$ tiveron maiores problemas 
debido ao uso constante dos portátiles abalar que participan no Edixgal (libro dixital).

Neste proxecto participa a maioría do profesorado que imparte clase nas devanditas aulas, ademais participaron voluntaria e activamente outros profesores que acudiron as sesión de formación durante os cursos anteriores.

A diversidade de niveis entre o profesorado é moi acusado, sendo o maior problema atopado para o desenrolo dos contidos. A adaptación é complicada e en ocasións provoca que o ritmo de ensinanza sexa lento.

Estamos levando a cabo unha formación do profesorado ao longo destes cursos coa coordinación e colaboración do centro de formación e recursos (CFR e CAFI).

Para levar adiante estes contidos empregamos a aula virtual moodle (http://www.edu.xunta.es/centros/ceipraquelcamacho/au lavirtual) da web do centro .

Tamén se elaboraron varios blogues para a realización da formación Abalar (http://obradoiroabalar.blogspot.com), (http://competenciasdixitais.wordpress.com/)

(http://abalarpdi.blogspot.com/).

Para o uso do libro dixital temos o blog: http://edixgal.blogspot.com.es/

Empregamos na Aula Abalar diferentes ferramentas web 2.0., o servidor do centro, a PDI e a Rede Edmodo: como aula virtual, rede social e blogs.

Nas aulas TIC ( $5^{\circ}$ E.P.) comezou a funcionar un novo elemento: o libro de texto dixital. No noso centro é nun dos que empezou de xeito experimental. Aínda que o potencial educativo sexa alto, ata o momento o único que deu foron dores de cabeza ao profesorado dos cursos implicados.

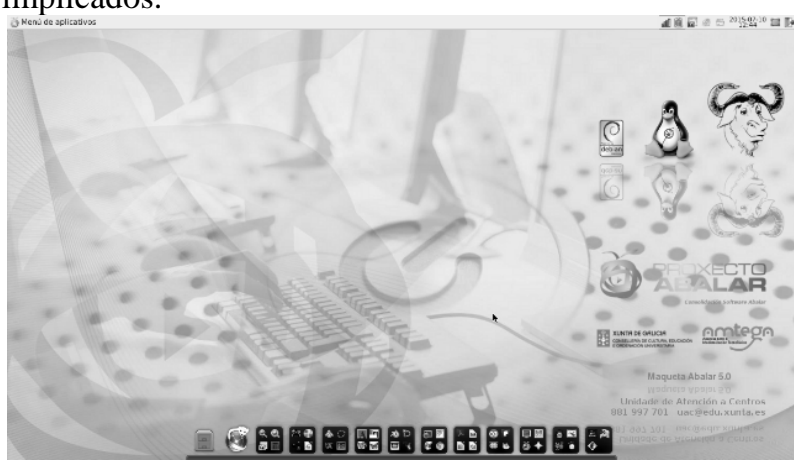

Figura 6. Maqueta Abalar 5.0.

Intentamos seguir o protocolo que se nos pide dende a Consellería para levar a cabo o proxecto durante este e os próximos cursos:

- Desenvolvemos o programa segundo as pautas establecidas no proxecto presentado, que se incorporou ao proxecto educativo do centro.

- O centro, realizou unha divulgación da iniciativa entre toda a comunidade educativa, con especial incidencia no alumnado e nas familias, de xeito que se proporcionou a información necesaria e se realizo a adecuada sensibilización en relación con esta programa.

- O profesorado implicado e o equipo directivo, participou nas actividades de formación vinculadas ao proxecto que se planifico tanto desde o centro como desde a Consellería de Cultura, Educación e Ordenación Universitaria.
- O centro garantizou a participación activa da persoa coordinadora do proxecto e dalgún membro do equipo directivo nas reunións de traballo que desde a Administración educativa se establezan.

Esperemos que nos próximos cursos e cos contidos xa máis formados do libro dixital, poidamos sacarlle maior partida a todo o material.

En principio ao ser experimental custounos un pouco a adaptación á nova plataforma. Pero grazas ao bo facer das titoras de quinto e á súa grande implicación para solucionar calquera dúbida ou problema o proxecto vai saíndo adiante.

\section{Conclusións}

A experiencia de traballo por proxectos coas TIC (Abalar, Edixgal), resulta moi interesante. Este xeito de aprender enriquece o proceso ensino aprendizaxe, as familias comprométense máis e o alumnado está máis motivado. As ferramentas TIC e o acceso educativo a internet enriquece $o$ noso traballo, faino máis significativo, porque o alumnado síntese parte do proceso e aprenden a chegar a información e a contidos que de ningún outro xeito poderíamos programar.

Un dos desafíos do dinamizador TIC/Abalar, e axudar aos teus compañeiros a superar a súa tecnofobia.

Citarei algúns deles:

- Non temos tempo. A formación TIC (cursiños obrigatorios ou voluntarios), supón tempo que vai máis alá da nosa labor docente.

- Dificultades técnicas. Os equipos non sempre funcionan ben, e ademais dispoñen dunha deficiente conexión.

- As TIC enredan ao alumnado. É difícil controlar a toda unha clase de 25 alumnos conectados a Internet, sen saber se están consultando as páxinas web requiridas.

- Información pouco fiable. Non nos podemos fiar de todo o que aparece en Internet.

- Os alumnos non aprenden. Limítanse a copiar sen ler, abusan de determinadas páxinas como Wikipedia para facer os traballos, e o que deben facer é aprender a contrastar a información que reciben.

- $\quad$ Non temos experiencia coas TIC. Non paga a pena formarse nas novas tecnoloxías.

- AS TIC non aportan nada a miña materia. Non necesitamos netbooks, nin proxecto Abalar para ensinar ao noso alumnado.

- A metodoloxía tradicional sempre nos funcionou, e agora non ten porque ser unha excepción.

A posibilidade de dispoñer dunha intranet no entorno educativo é algo moi positivo para o Centro, xa que se converte nun entorno seguro e privado para que os docentes galegos, poidamos dispoñer de servizos de colaboración e comunicación como o correo EduXunta ou portais como o XADE e fprofe.

Centrareime principalmente no Servidor Abalar, que aporta ao meu Centro tanto servizos de rede, que nos 
descargan de bastante traballo aos coordinadores abalar (co servidor de IP's dinámicas e as sempre problemáticas actualizacións), e os servizos de usuario, que me permiten restaurar os equipos que fallan, acceder no futuro ás web dinámicas (Drupal, Moodle e Coppermine), e o acceso ao repositorio de recursos educativos do noso Centro, que curso a curso o profesorado imos aumentando con traballos elaborados por nós mesmos, ou descargándoos directamente do espazoAbalar. Posiblemente esta sexa a ferramenta do servidor menos valorada e máis infrautilizada, a pesar de que nos ofrece a posibilidade de dispoñer dun espazo de almacenamento gratuíto, catalogación e busca de recursos educativos a disposición tanto do profesorado como do alumnado.

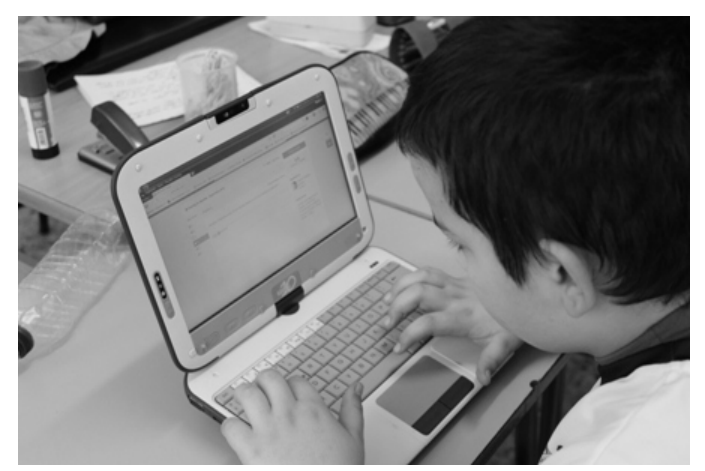

Imagen 1. Alumno cos miniportátiles Abalar

E finalmente, se cadra unha das funcións máis importantes, e axudar aos nosos alumnos e alumnas a entender a rede a as súas posibilidades comunicativas e de organización da información dun xeito titorizado, no que ademais hai que cumprir unhas normas. Deste xeito estaremos contribuíndo á súa formación non só de cara ao ensino formal senón tamén como persoas do século XXI, usuarios/as actuais ou próximos de redes sociais abertas nas que en moitos casos ninguén lles orienta nin axuda a manexar.

\section{Referencias Bibliográficas}

$\mathrm{B} \log$

Edixgal.

Disponible: http://edixgal.blogspot.com.es/

Blog de aula $5^{\circ}$ EP do CEIP Raquel Camacho (A Coruña)

Disponible: http:/quintosmegas.blogspot.co m.es/

Portal educativo Xunta de Galicia. Disponible: http://www.edu.xunta.es

Portal Amtega. Xunta de Galicia. Disponible: http://amtega.xunta.gal/

Portal CEDEC. Proxecto Abalar. Disponible: http://cedec.ite.educacion.es/kub yx/47-proxecto-abalar-y-el-software-libre

Resolución do 30 de abril de 2015, da Dirección Xeral de Educación, Formación Profesional e Innovación Educativa, pola que se convoca a selección de centros para participar no proxecto Educación Dixital E-DIXGAL durante o curso 2015/2016.

Rodríguez Machado, E. “El Proyecto Abalar: formación y uso del profesorado y alumnado en un centro educativo digital” Revista OGE (Organización y Gestión Educativa) N N 3 Mayo 2012

Rodríguez Machado. "Educación Física 2.0.“ RevistaDIM - No24 Xaneiro 2013 ISSN: 1699-3748. Red DIM. Grupo de investigación DIM.

Disponible: http://dim.pangea.org/revistaDIM2 4/revistanewseleccionbuenaspracticas.htm\#edu cacionfisica

Rodríguez Machado, E. Aproximación teórica a Edixgal. Libro digital de Educación Física. Sportis: Revista Técnico-Científica del Deporte Escolar, Educación Física y Psicomotricidad, ISSN-e 2386-8333, Vol. 1, №. 1, 2015, págs. 2-15. Disponible: http://sportis.es/revista/index.php/S cientificTJ/index 